\title{
A N IMAL
}

\section{PRODUCTION}

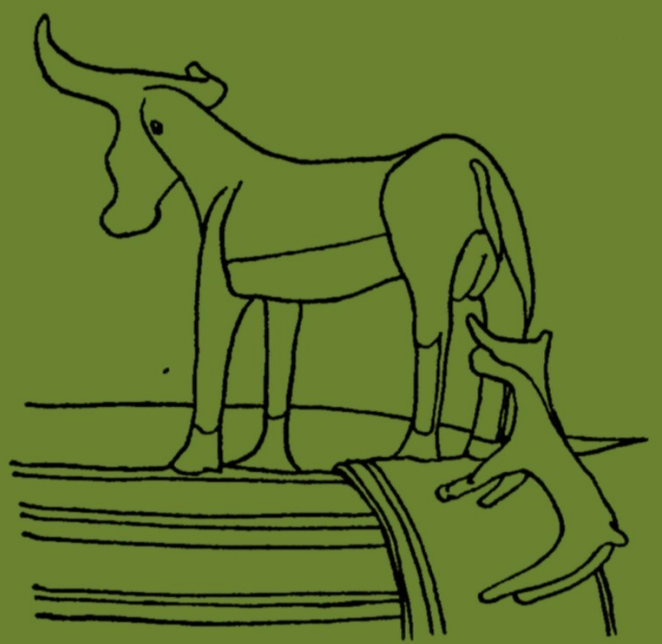

JOURNAL OF THE BRITISH SOGIETY OF ANIMAL PRODUGTION

\section{LONGMAN}




\section{INFORMATION FOR CONTRIBUTORS TO ANIMAL PRODUCTION}

Detailed notes for guidance in the preparation of manuscripts are printed in Volume 25: pages ix to xxii. A few general points are given below.

Animal Production publishes reports in English of original work in the field of animal production or in any related scientific field. The Editors will consider articles on any aspect of research or development, providing the work described has been carried out in a systematic way, and articles critically reexamining published information. Reviews of literature are not accepted. Papers presenting a detailed description of a technique or of equipment will be considered only if the technique or equipment has been used in experiments, the results of which are included in the same paper or a subsequent paper within a series. Results of research work which do not warrant presentation as a full paper may be submitted for consideration as Notes. Notes are not intended for the publication of interim results. They must not exceed 2000 words or the equivalent inclusive of tables and illustrations. Proprietary preparations used as a source of material in experimental comparisons may be referred to by their trade names, in the Material and Methods section only, if this is seen as helpful to readers. Papers describing work designed merely to evaluate proprietary preparations will not be accepted.

Papers are published on the understanding that they have not been and, with the exception of authors' abstracts, will not be published elsewhere without the Editor's written permission. Authors' abstracts can be reproduced if full acknowledgement of the source is made.

Manuscripts should be typewritten on one side of the paper in double-line spacing with wide margins. Each page and the lines on each page should be numbered. Three, or exceptionally two, copies, one of which must be the original, of the typescript and illustrations should be sent to

$$
\begin{aligned}
& \text { Professor J. A. F. Rook, } \\
& \text { Animal Production, } \\
& \text { The Hannah Research Institute, } \\
& \text { Ayr KA6 5HL, Scotland }
\end{aligned}
$$

Manuscripts are not returned with proofs; authors should therefore retain copies.

Units of measurement. The International System of Units (SI) should be used, with the recommendations and modifications in Quantities, Units and Symbols, The Royal Society, London, 1975, and Metric Units, Conversion Factors and Nomenclature in Nutritional and Food Sciences, The Royal Society, London, 1972-reproduced in Proc. Nutr. Soc. 31: 239-247, 1972.

Symbols and abbreviations. Authors should consult the notes prepared for guidance. Levels of statistical significance must be clearly indicated.

Illustrations. The same material should not normally be presented in tables and figures. Legends should be typed on a separate sheet.

(a) Diagrams should be drawn in Indian ink, about twice the size of the finished block, on Bristol board, stout tracing paper or plastic film.

[Continued on inside back cover

Front cover centrepiece; by Dr. Anne Hurst; Figures of cow and calf on bronze bowl from the Halstatt prehistoric cemetery. Cast in solid bronze in the Salz kammergut, Upper Austria. 